\title{
Pengaruh Bimbingan Kelompok Melalui Zoom Meeting Teknik Johari Window dalam Meningkatkan Penerimaan Diri Siswa
}

\author{
Afny Rumaysya Khulwah ${ }^{*}$, Heru Mugiarso $^{2}$ \\ 1,2 Program Studi Bimbingan dan Konseling, Universitas Negeri Semarang, Indonesia. \\ *) Corresponding author, $\equiv$ e-mail: afnyrumaysya78@gmail.com
}

\begin{tabular}{ccc}
\hline Received: & Accepted: & Published: \\
03 August 2021 & 15 October 2021 & 31 December 2021 \\
\hline
\end{tabular}

\section{Abstract}

The purpose of this study was to determine the effect of group guidance services through zoom meetings with the Johari Window technique to increase student self-acceptance. Current research used experimental method with one group pre-test post-test design. The sampling technique used was purposive sampling with total of 8 sample. The data collection method is self-acceptance scale with 4 indicators and 52 items. The validity of the instrument verified using the product moment formula obtained $r$ table value $=0.312$. While the reliability of the instrument verified with the Cronbach alpha formula, the results of the Cronbach Alpha were 0.774 . The data analysis technique used is descriptive analysis and Wilcoxon test. The results of the descriptive analysis showed that the level of student self-acceptance before being given treatment was in the medium category. Meanwhile, before being given treatment, they were in the high category. Based on the results of the Wilcoxon test, it is known that Asymp. Signature. (2-tailed) worth 0.012 . Because 0.012 is smaller than 0.05 , it can be said that group guidance services through meetings with the johari technique have a significant effect on increasing student self-acceptance.

Keywords: Self-Acceptance, Guidance Groups, Johari Window

\begin{abstract}
Abstrak
Tujuan dari penelitian ini adalah untuk mengetahui pengaruh layanan bimbingan kelompok melalui zoom meeting dengan teknik johari window dapat berpengaruh terhadap peningkatan penerimaan diri siswa. Jenis penelitian yang digunakan dalam penelitian ini adalah penelitian eksperimen dengan desain one group pretest-posttest. Teknik pengambilan subjek penelitian yang digunakan adalah purposive sampling sejumlah 8 siswa. Alat pengumpul data yang digunakan dalam penelitian ini yaitu skala penerimaan diri sebanyak 4 indikator dan 52 item. Validitas instrumen diuji menggunakan rumus product momen didapat nilai rtabel $=0.312$. Sedangkan reliabilitas instrumen diuji dengan rumus cronbach alpha diperoleh hasil nilai Cronbach Alpha sebesar 0,774. Teknik analisis data yang digunakan adalah analisis deskripstif dan analisis uji Wilcoxon. Hasil analisis deskripstif menunjukkan bahwa tingkat penerimaan diri siswa sebelum diberikan treatment dalam kategori sedang. Sedangkan sesudah diberikan treatment berada dalam kategori tinggi. Berdasarkan output hasil uji Wilcoxon diketahui Asymp. Sig. (2-tailed) bernilai 0,012 . Karena 0,012 lebih kecil dari 0,05, maka dapat disimpulkan bahwa layanan bimbingan kelompok melalui zoom meeting dengan teknik johari window berpengaruh terhadap peningkatan penerimaan diri siswa.
\end{abstract}

Kata Kunci: Penerimaan Diri, Bimbingan Kelompok, Johari window 


\section{PENDAHULUAN}

Penerimaan diri merupakan suatu tingkatan kesadaran individu tentang karakteristik kepribadiannya, akan kemauan untuk hidup dengan keadaan tersebut (Hurlock, 2006). Penerimaan diri adalah sejauh mana seseorang dapat menyadari dan mengakui karakteristik pribadi dan menggunakannya dalam menjalani kelangsungan hidupnya. Sikap penerimaan diri ditunjukkan oleh sikap pengakuan seseorang terhadap kelebihankelebihan sekaligus menerima kelemahankelemahan tanpa menyalahkan orang lain dan memiliki keinginan untuk terus mengembangkan diri. Penerimaan diri merupakan dasar dalam memilih dan mengejar tujuan yang penting sebagai upaya untuk mencapai kebahagiaan baik kebahagiaan jangka pendek maupun jangka panjang (Bernard, 2013).

Individu yang memiliki penerimaan diri akan mengetahui segala kelebihan dan kekurangannya, dan mampu mengelolanya (Sari \& Nuryoto, 2002). (Schultz, 1991) sependapat dengan hal tersebut menyatakan bahwa orang yang menerima dirinya adalah orang yang dapat menerima kelemahan-kelemahan dan kekuatankekuatan mereka tanpa keluhan atau kesusahan. Berdasarkan beberapa pendapat ahli tersebut, dapat disimpulkan bahwa penerimaan diri adalah kemampuan individu dalam mengakui keadaan dalam diri, baik itu kelebihan maupun kelemahan dan mereka dapat hidup bahagia dengan keadaan tersebut.
Berdasarkan wawancara dengan Guru BK, terdapat beberapa siswa yang merasa kurang percaya diri dan minder terhadap dirinya sendiri karena sisi negatif yang ia miliki. Padahal percaya diri itu berasal dari diri seseorang atau pribadi itu sendiri yang ada nyatanya dan tidak di buat-buat. Siswa tersebut merasa dirinya tidak mampu melakukan suatu hal yang dilakukan oleh teman-temannya tanpa berusaha terlebih dahulu. Padahal setiap individu itu memiliki kelebihan dan kekurangan masing-masing. Jika siswa mempunyai percaya diri yang kuat pasti mampu menerima apa yang dia miliki pada dirinya baik dari kekurangannya maupun kelebihannya. Sehingga dengan hal itu dapat mengetahui seberapa besar tingkat penerimaan diri yang dimiliki. Serta dapat meningkatkan rasa penerimaan diri dalam siswa.

Indikator penerimaan diri yaitu pertama memiliki gambaran yang postif tentang dirinya berdasarkan fenomena di lapangan yaitu masih ada siswa yang memandang negatif dirinya, yaitu hanya melihat kekurangannya tanpa melihat kelebihan yang ada pada dirinya. Kedua, dapat mengatur dan dapat bertoleransi dengan rasa frustasi dan kemarahannya, berdasarkan hasil wawancara dengan Guru BK ada beberapa siswa yang belum bisa mengontrol emosinya misalnya ketika diejek oleh temannya siswa itu langsung membalasnya. Ketiga, dapat berinteraksi dengan orang lain tanpa memusuhi mereka apabila orang lain beri kritik, berdasarkan wawancara dengan Guru BK, siswa 
memang selalu diajarkan oleh guru untuk selalu berinteraksi dengan temannya yang berbeda kelas atau selalu menjaga kerukunan berteman dengan siapa saja, hal itu bertujuan agar siswa tidak hanya percaya diri ketika dikelasnya saja, melainkan juga harus mempunyai rasa percayaan diri yang tinggi agar dapat mempermudah dalam berinteraksi dengan individu lainnya. Keempat, dapat mengatur keadaan emosi mereka, berdasarkan wawancara dengan guru bk, masih ada beberapa siswa yang belum mampu mengatur keadaan emosinya misalnya ketika mendapatkan celaan dari temannya atau orang lain.

Salah satu layanan yang dapat digunakan adalah layanan bimbingan kelompok. Layanan bimbingan kelompok merupakan layanan bimbingan yang diberikan dalam suasana kelompok. Bimbingan kelompok merupakan bantuan terhadap individu yang dilaksanakan dalam situasi kelompok. Masalah yang dibahas dalam bimbingan kelompok adalah masalah yang dialami bersama dan tidak rahasia, baik menyangkut masalah pribadi, sosial, belajar, maupun karir (Nurihsan, 2006). Prayitno \& Amti (2004) menyatakan bimbingan kelompok di sekolah merupakan kegiatan informasi kepada sekelompok siswa untuk membantu mereka menyusun rencana dan keputusan yang tepat.

Salah satu cara untuk meningkatkan pemahaman diri pada individu adalah dengan menggunakan model permainan Johari Window. Model permainan Johari Window digunakan untuk menggambarkan kesadaran diri (self-awareness) yang merupakan salah satu dimensi dari pemahaman diri (South, 2007). Joseph Luft dan Harrington Ingham mengembangkan konsep Johari Window sebagai perwujudan bagaimana seseorang berhubungan dengan orang lain yang digambarkan sebagai sebuah jendela. Jendela tersebut terdiri dari 4 area diantaranya area terbuka, area buta, area tersembunyi, dan area gelap/tidak diketahui (Luft \& Ingham, 1961; Robertson, 2016).

Berdasarkan hasil wawancara dengan Guru Bimbingan Konseling di SMP N 3 Karanganyar, peneliti mendapatkan informasi bahwa penerimaan diri yang dimiliki oleh siswa umumnya termasuk dalam kategori baik. Hal itu karena siswa berada dalam lingkungan pemukiman yang tidak terlalu kota namun juga tidak termasuk dalam pemukiman desa. Tetapi masih terdapat sekitar 15\%-20\% siswa yang kurang memiliki penerimaan diri. Hal itu dapat dilihat ketika sedang ada tugas harian dikelas. Siswa masih merasa kurang percaya diri untuk menyampaikan pendapat atau jawaban sesuai dengan kemampuan yang dimilikinya. Informasi itu diperoleh melalui beberapa guru mata pelajaran yang melaporkan kepada guru BK. Karena pandemi, sekolah harus dilakukan dengan cara daring, namun masih ada siswa yang kurang memiliki kesadaran diri untuk mengerjakan tugas yang telah diberikan oleh guru.

\section{METODE}

Jenis kajian yang digunakan dalam penelitian ini adalah pendekatan 
eksperimen. Peneliti menggunakan eksperimen karena dalam hal ini peneliti menggunakan suatu perlakuan untuk mengetahui akibat dari perlakuan tersebut. Jenis desain penelitian yang digunakan dalam penelitian ini adalah one group pretestposttest. Pengukuran dilakukan sebanyak dua kali yaitu sebelum dan sesudah diberi perlakuan. Perlakuan yang dimaksud yaitu layanan bimbingan kelompok melalui zoom meeting dengan teknik johari window. Subjek dalam penelitian ini, peneliti mengambil sampel dikelas IX SMP N 3 Karanganyar sebanyak 8 orang. Teknik pengambilan subjek penelitian yang digunakan dalam penelitian ini adalah purposive sampling. Purposive sampling yaitu teknik penentuan sampel dengan pertimbangan tertentu. Berikut pertimbangan yang digunakan dalam pengambilan sampel dengan teknik purposive sampling, diantaranya yaitu: Sebanyak delapan Siswa Kelas IX SMP Negeri 3 Karanganyar yang memiliki penerimaan diri rendah sesuai dengan rekomendasi guru bimbingan konseling.
Sebelum diberikan treatment siswa diilakukan PreTest. Pre-test bertujuan untuk mengetahui gambaran penerimaan diri siswa sebelum diberikan treatment. Treatment yang diberikan yaitu berupa layanan bimbingan kelompok dengan teknik Johari Window sebanyak 6 kali pertemuan dengan alokasi waktu satu kali pertemuan 1 x 40 menit. Setelah diberikan treatment sebanyak 6 kali pertemuan kemudian peneliti melakukan PostTest kepada siswa yang bertujuan untuk mengetahui keberhasilan dalam pelaksanaan treatment dan untuk mengetahui adanya perbedaan tingkat penerimaan diri pada siswa yang telah diberikan perlakuan.

\section{HASIL TEMUAN}

Berikut diuraikan gambaran tingkat penerimaan diri siswa dari hasil sebelum dan sesudah diberikan treatment layanan bimbingan kelompok melalui zoom meeting dengan teknik johari window. Hasil pretest dan posttest dapat dilihat pada Tabel 2.

Tabel 2 Hasil Pre-test dan Post-test Skala Penerimaan Diri

\begin{tabular}{clcccccc}
\hline No & \multicolumn{2}{c}{ Nama } & \multicolumn{3}{c}{ Hasil Pre-Test } & \multicolumn{3}{c}{ Hasil Post-Test } \\
\hline & & Skor & $\%$ & Kategori & Skor & $\%$ & Kategori \\
\hline 1 & TZA & 62 & $59 \%$ & Sedang & 76 & $72 \%$ & Tinggi \\
2 & RIM & 53 & $50 \%$ & Sedang & 74 & $70 \%$ & Tinggi \\
3 & PM & 64 & $61 \%$ & Sedang & 74 & $70 \%$ & Tinggi \\
4 & NAS & 69 & $65 \%$ & Sedang & 88 & $83 \%$ & Tinggi \\
5 & WMM & 55 & $52 \%$ & Sedang & 73 & $69 \%$ & Tinggi \\
6 & NF & 67 & $64 \%$ & Sedang & 78 & $74 \%$ & Tinggi \\
7 & NSF & 57 & $54 \%$ & Sedang & 73 & $69 \%$ & Tinggi \\
8 & APN & 58 & $55 \%$ & Sedang & 73 & $69 \%$ & Tinggi \\
\hline
\end{tabular}




\begin{tabular}{lllllll}
\hline Rata-Rata & $\mathbf{6 1}$ & $\mathbf{5 8 \%}$ & Sedang & 76 & $72 \%$ & Tinggi \\
\hline
\end{tabular}

Berdasarkan data pada Tebel 2 dapat diketahui adanya perbedaan tingkat penerimaan diri siswa SMP $\mathrm{N} \quad 3$ Karanganyar sebelum diberikan treatment berupa layanan bimbingan kelompok melalui zoom meeting dengan teknik Johari Window, termasuk dalam kategori sedang dengan skor rata-rata yaitu sebesar 61 dengan presentase sebesar $58 \%$. Kemudian skor meningkat setelah diberikan treatment berupa layanan bimbingan kelompok melalui zoom meeting dengan teknik johari window, termasuk dalam kategori tinggi dengan skor rata-rata yaitu sebesar 76 dengan presentase sebesar $72 \%$.

Selanjutnya berdasarkan output hasil uji Wilcoxon diketahui Asymp. Sig. (2tailed) bernilai 0,012. Karena 0,012 lebih kecil dari 0,05, maka dapat disimpulkan bahwa hipotesis diterima. Artinya ada perbedaan antara penerimaan untuk pretest dan posttest. Sehingga dapat dinyatakan bahwa layanan bimbingan kelompok melalui zoom meeting dengan teknik johari window berpengaruh pada peningkatan penerimaan diri siswa SMP $\mathrm{N} 3$ Karanganyar.

\section{PEMBAHASAN}

Penerimaan diri merupakan suatu sikap dimana individu memiliki penghargaan yang tinggi terhadap segala kelebihan dan kekurangan dirinya sendiri tanpa menyalahkan orang lain dan mempunyai keinginan untuk mengembangkan diri secara terus menerus.
Dengan penerimaan diri yang baik, individu menjadi lebih menyadari siapa dirinya, apa yang menjadi kekurangannya, apa yang menjadi kelebihannya yang ini bisa digunakan untuk menghadapi masalah apa yang sedang dihadapinya. Dukungan sosial juga memberikan pengaruh tehadap penerimaan diri remaja (Hafni, 2020).

Hasil kajian ini juga senada dengan hasil penelitian (Sitorus et al., 2019) yang menyatakan bahwa bimbingan kelompok dengan metode permainan meningkatkan penerimaan diri siswa. Hal itu dapat dilihat dari jumlah subjek penelitian berada pada kategori sedang, artinya siswa mencapai tingkat penerimaan diri yang sedang pada setiap aspeknya. Sedangkan penelitian milik peneliti berbeda dengan metode yang digunakan pada menggunakan teknik johari window. Dari penelitian ini diperoleh hasil bahwa layanan bimbingan kelompok berpengaruh pada peningkatkan penerimaan diri siswa di SMP N 3 Karanganyar. Dengan presentase rata-rata nilai pretest termasuk dalam kategori sedang yaitu $(58 \%)$ dan presentase rata-rata nilai posttest termasuk dalam kategori tinggi yaitu (72\%). Hal ini dapat dipahami bahwa sesungguhnya penerimaan diri siswa merupakan aspek psikologis yang sangat sederhana yang berdasarkan penelitian (Mostavi, dkk, 2020) bahwa penerimaan diri tidak berkontribusi dengan penerimaan diri siswa.

Selanjutnya penelitian dari Wijayanti dkk (2020) diperoleh hasil bahwa terjadi 
peningkatan penerimaan diri setelah diberikan layanan bimbingan kelompok menggunakan teknik manajemen diri. Walaupun terdapat perbedaan, yaitu penelitian sebelumnya menggunakan layanan bimbingan kelompok sedangkan dalam penelitian ini menggunakan layanan bimbingan kelompok dengan teknik Johari Window. Namun persamaannya yaitu dengan layanan bimbingan kelompok berpengaruh terhadap peningkatan penerimaan diri siswa.

Gambaran penerimaan diri pada delapan siswa kelas IX sebelum diberikan treatment layanan bimbingan kelompok melalui zoom meeting dengan teknik Johari Window ditunjukkan dengan sikap seperti kurang percaya diri, suka berpikiran negatif terhadap dirinya sendiri, serta malu dengan latar belakang dirinya sendiri. Gambaran penerimaan diri diperoleh dari hasil wawancara dengan Guru BK dan skala penerimaan diri yang diisi oleh masingmasing siswa. Sebelum diberikan treatment melalui layanan bimbingan kelompok melalui Zoom Meeting dengan teknik Johari Window siswa memiliki penerimaan sedang dengan rata-rata presentase yaitu $58 \%$.

Kemudian, kedelapan siswa tersebut diberikan treatment layanan bimbingan kelompok melalui zoom meeting dengan teknik Johari Window. Dari hasil treatment yang telah diberikan, peningkatan penerimaan diri setiap siswa diukur kembali menggunakan skala penerimaan diri. Gambaran penerimaan diri siswa setelah diberikan treatment daitunjukkan dengan sikap seperti siswa mampu mengetahui tentang dirinya, dan mampu mengetahui bagaimana orang disekitar menilai dirinya, dengan begitu konseli mampu menerima keadaan yang ada pada dirinya.

Setelah diberikan treatment melalui layanan bimbingan kelompok melalui zoom meeting dengan teknik johari window menunjukkan gambaran tingkat penerimaan diri dalam kriteria tinggi dengan rata-rata presentase yaitu $72 \%$. Dengan demikian terjadi peningkatan sebesar $14 \%$.

Berdasarkan hasil penerimaan diri setelah diberikan treatment layanan bimbingan kelompok melalui zoom meeting dengan teknik Johari Window menunjukkan bahwa peningkatan tertinggi terdapat pada siswa RIM dan peningkatan paling rendah terjadi pada siswa PM. Adanya peningkatan tersebut menunjukkan bahwa layanan bimbingan kelompok melalui zoom meeting dengan teknik Johari Window berpengaruh terhadap peningkatan penerimaan diri siswa karena memang disamping layanan bimbingan kelompok yang diberikan juga teknik Johari Window juga sangat sesuai bagi anggota kelompok untuk mengenali dirinya sendiri sedalam mungkin (Halpern, 2009).

Pada awal layanan bimbingan kelompok siswa belum mau untuk menyampaikan pendapatnya. Anggota kelompok masih kurang terbuka dan belum percaya diri untuk menyampaikan pendapatnya masing-masing. Namun pada pertemuan berikutnya siswa sudah mau untuk berpendapat pada saat kegiatan bimbingan kelompok. Dari siswa yang tidak mau menyampaikan pendapatnya karena kurang percaya diri dan takut salah sampai 
siswa sudah berani dan menyampaikan pendapatnya. Hal ini dikarenakan bimbingan kelompok merupakan salah satu layanan yang dapat mengaktifkan peserta dalam hal ini siswa melalui dinamika kelompok sehingga konselor dapat memahami respon siswa mulai dari awal sampai akhir sesuai dengan topik yang dibahas (Pohan \& Indra, 2020).

Kegiatan layanan bimbingan kelompok dilaksanakan sesuai dengan prosedur yang telah direncanakan. Meskipun penelitian ini telah dilaksanakan semaksimal mungkin, akan tetapi penelitian ini memiliki keterbatasan, diantaranya yaitu Siswa memiliki kesibukan dengan pelajaran disekolah, sehingga peneliti kesulitan menentukan waktu luang siswa. Peneliti meminta bantuan kepada guru BK untuk membantu mengkomunikasikan dengan siswa. Dan selanjutnya Peneliti tidak melakukan tindak lanjut untuk melihat apakah perubahan tersebut masih terjadi pada siswa yang diteliti.

Implikasi dari penelitian ini yaitu siswa mengetahui siapakah dirinya itu kemudian siswa juga mengetahui penilaian orang lain tentang dirinya, dengan diberikannya treatment tersebut siswa mampu menyikapi penilaian tentang dirinya yang telah dilakukan oleh orang lain. Yaitu siswa mampu menerima penilaian tersebut, mampu bertoleransi dan siswa menjadi lebih terbuka dan orang lain juga bisa mengetahui sikap dari siswa/subjek yang telah dipilih secara random ketika pelaksanaan treatment yaitu layanan bimbingan kelompok dengan teknik Johari Window. Dari hasil analisis secara keseluruhan, terlihat terdapat perbedaan penerimaan diri siswa antara sebelum dan sesudah diberikan treatment layanan bimbingan kelompok melalui zoom meeting dengan teknik Johari Window.

Saran untuk peneliti selanjutnya diharapkan dapat menggunakan hasil kajian ini sebagai bahan acuan pada penelitian yang selanjutnya dengan menggunakan layanan lainnya dalam meningkatkan penerimaan diri siswa.

\section{SIMPULAN}

Kesimpulan dari kajian ini bahwa layanan bimbingan kelompok melalui Zoom Meeting dengan teknik Johari Window memberi pengaruh yang signifikan terhadap peningkatkan penerimaan diri siswa. Penggunaan media Zoom Meeting dapat menjadi salah satu pilihan alternatif bagi Guru BK/Konselor untuk melaksanakan layanan bimbingan kelompok terutama dalam masa pandemi Covid-19.

\section{UCAPAN TERIMA KASIH}

Terimakasih kepada Siswa Kelas IX SMP N 3 Karanganyar atas partisipan dan kesediannya untuk menjadi responden selama penelitian dilaksanakan.

\section{DAFTAR PUSTAKA}

Ardhistia Sheilla. (2015). Perbedaan penerimaan diri antara lansia yang tinggal di panti wreda berdasarkan keputusan sendiri dan bukan berdasarkan keputusan sendiri. Yogyakarta: Universitas Sanata Dharma Yogyakarta.

Bernard, M. E. (2013). The strength of self- 
acceptance: Theory, Practice and Research. Springer New York.

Chaplin, J. P. (2014). Kamus lengkap psikologi. Penerjemah. Jakarta: Raja Grafindo Persada.

Sari, E. P., \& Nuryoto, S. (2002). Penerimaan diri pada lanjut usia ditinjau dari kematangan emosi. Jurnal Psikologi, 29(2), 73-88.

Hafni, M. (2020). Effectiveness of social support with adolescent's selfacceptance in post-divorce parents. INSPIRA: Indonesian Journal of Psychological Research, 1(2), 38-42. https://doi.org/10.32505/inspira.v1i2.2 838.

Halpern, H. (2009). Supervision and the Johari window: a framework for asking questions. Education for Primary Care, 20(1), 10-14.

Hidayah, E. M., \& Mu'awanah, E. (2009). Bimbingan konseling islami di sekolah dasar. Jakarta: Bumi Aksara.

Hurlock, E. B. (2006). Psikologi perkembangan suatu pendekatan sepanjang rentang kehidupan. Edisi kesembilan. Alih bahasa: Istiwidayanti, Soedjarwo. Jakarta: Erlangga.

Izzati, A \& Waluya, O, T. (2012). Gambaran penerimaan diri pada penderita psoriasis. Jurnal Psikologi. 10(2), 68-78.

Luft, J., \& Ingham, H. (1961). The Johari Window: a graphic model of awareness in interpersonal relations. Human relations training news, 5(9), 6-7.

Mostafavi, H., Yoosefee, S., Seyyedi, S. A., Rahimi, M., \& Heidari, M. (2020). The impact of educational motivation and self-acceptance on creativity among high school students. Creativity Research Journal, 32(4), 378-382.

Nurihsan, A. J. (2006). Bimbingan \& konseling dalam berbagai latar kehidupan. Reftika Aditama.

Prayitno, E. A., \& Amti, E. (2004). Dasardasar bimbingan dan konseling. Jakarta: Rineka Cipta.

Pohan, R. A., \& Indra, S. (2020). Efektivitas layanan bimbingan kelompok dalam meningkatkan kegiatan merespon pembelajaran. Islamic Counseling: Jurnal Bimbingan Dan Konseling Islam, $\quad 4(1), \quad$ 17-30. https://doi.org/10.29240/JBK.V4I1.128 0 .

Robertson, F. (2016). The Johari Window. In Gower handbook of internal communication (163-168). Routledge.

Sari, W. P., Umari, T., \& Arlizon, R. Pengaruh layanan bimbingan kelompok terhadap peningkatan penerimaan diri siswa kelas X Ak Smk labor binaan FKIP Unri Pekanbaru T.A 2015/2016 (Doctoral dissertation, Riau University).

Schultz, D. (1991). Psikologi pertumbuhan, model-model kepribadian sehat, terj. Yustinus, Yogyakarta: Kanisius.

Sitorus, M. W., Badrujaman, A., \& Fitri, S. (2019). Pengaruh layanan bimbingan kelompok dengan metode permainan terhadap penerimaan diri siswa. ENLIGHTEN: Jurnal Bimbingan Konseling Islam, 2(1), 18-23.

South, B. (2007). Combining mandala and the Johari Window: An exercise in 
self-awareness. Teaching and Learning in Nursing, 2(1), 8-11.

Sugiyono. (2017). Metode penelitian pendidikan pendekatan kuantitatif, kualitatif, dan R\&D. Bandung: Alfabeta.

Wartana, Eka. (2012). A new way of thinking mind web konsep berpikir tanpa mikir. Jakarta: Gramedia.

Wijayanti, J., Sumarwiyah, S., \& Sucipto, S. (2020). Bimbingan kelompok teknik self management untuk meningkatkan penerimaan diri. Jurnal Prakarsa Paedagogia, 3(1). 